\title{
Calciphylaxis: a deadly disease tamed
}

\section{Introduction}

Calcific uremic arteriolopathy (CUA), also known as calciphylaxis, is a rare disease most frequently occurring in patients with either end-stage renal disease, chronic kidney disease (CKD), or even with normal kidney function patients, characterized by painful, indurate and ulcerative lesions often covered by dark eschar that is very tender and leads to necrosis following calcification and occlusion of small cutaneous arterioles. Lesions may be solitary or multiple, covering several body regions. The prognosis is generally not good, with mortality rate as high as $60-80 \%$ in patients with ulcerative disease. ${ }^{1}$

Keywords: calciphylaxis, end stage renal disease, hypertensive nephropathy, hyperlipidemia

\section{Case report}

A 74 years old lady known to have end stage renal disease secondary to long standing diabetic \& hypertensive nephropathy has been on hemodialysis since November 2010. Hypothyroidism on Eltroxin 150ug, hyperlipidemia on atorvastatin was admitted to the surgical department for debridement of her painful lower abdominal skin lesions which were progressing in size x 3 weeks. No history of recent contrast exposure, trauma or any local injections other system review was irrelevant. On examinations there were skin lesions (Figure 1) in the form of ill-defined black indurated tender plaques, varying in size, scattered only in her lower abdominal wall with no observed lymphadenopathy or discharge. Rest of her general and local examination was unremarkable. Her laboratory investigations showed: Serum creatinine 855umol/1, BUN 19umol/1, S-albumin/total proteins 27/55, CK Normal. Serum calcium 2.5umol/1. S-phosphorus $1.5 \mathrm{umol} / 1$, Ca $\mathrm{x}$ ph 3.75. PTH range over last 6 months was around (I molecule $13.5-21 \mathrm{pmol} / 1$. Wbc's $10 . \mathrm{Hgb} 8.9$ platelet 175 . ECG, ECHO \& Nuclear study all were normal, Parathyroid U/S and scan were normal. CT scan (Figure 2) showed subcutaneous calcifications, skin biopsy (Figure 3) shows intramural calcific deposits.

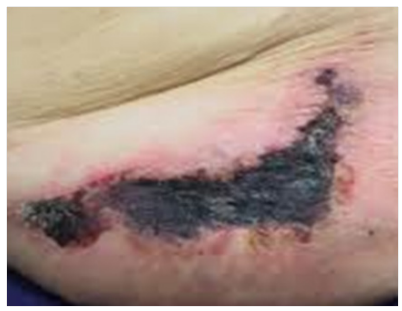

Figure I Before treatment.

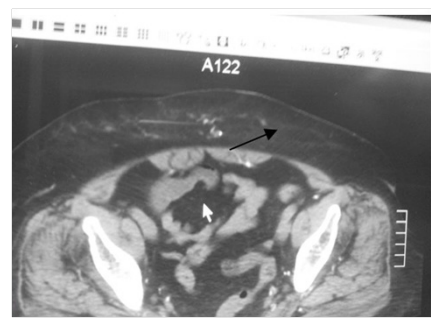

Figure 2 Sub cutaneous calcification (black arrow).
Volume 6 Issue 3 - 2018

\author{
Mohammad Anan \\ Department of Medicine, Nephrology unit, Al Amiri hospital, \\ Kuwait
}

Correspondence: Mohammad Anan, Nephrology Consultant Nephrology unit, Al Amiri hospital, Kuwait, Tel 0096566650756 , Email:manan40082003@yahoo.com

Received: June 07, 2018 | Published: June 27, 2018

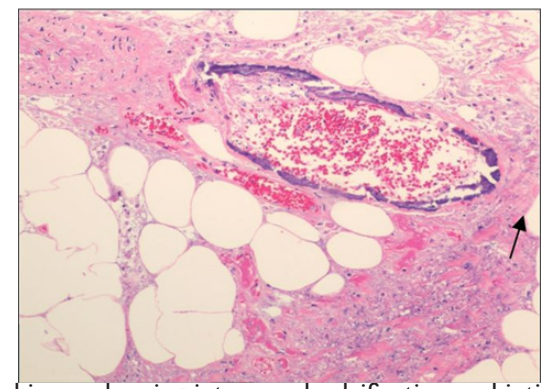

Figure 3 Skin biopsy showing intramural calcification and intimal hyperplasia in an arteriole of the subcutaneous.

\section{Results}

Marked improvement of calciphylaxis has now been reported with the use of intravenous sodium thiosulfate. Sodium thiosulfate is a potent antioxidant and it also increases the solubility of calcium deposits. Success has been reported in uremic and nonuremic calciphylaxis. ${ }^{2}$ The mainstay treatment of this condition was the use of sodium thiosulphate infusion of $25 \mathrm{gm}$ over 1 hour post hemodialysis for 6 months in addition to the other supportive measures (reduction of serum $\mathrm{Ca}$, Phos., CaxPh product and PTH to the recommended target levels). ${ }^{3}$ All of these measures led to complete cure of this condition after 6 months (Figure 4) and there was no surgical interference in this case. However, aggressive wound care and debridement of necrotic tissue may be necessary to avoid wound infection, sepsis, and some advice against debridement. Currently, there is no consensus on wound management. ${ }^{4}$

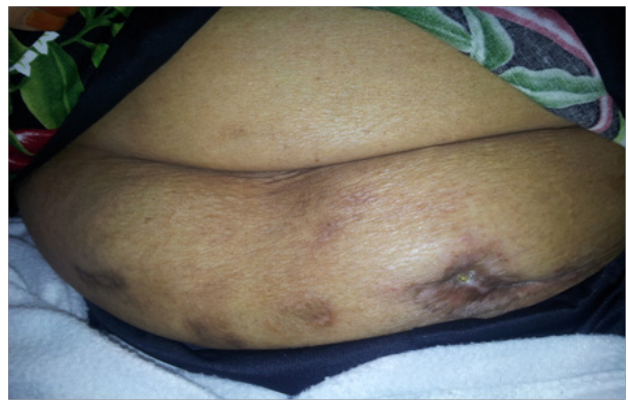

Figure 4 After 6 months of treatment. 


\section{Conclusion}

Early diagnosis and prompt treatment of calciphylaxis with sodium thiosulphate infusion improves the outcomes. ${ }^{5}$

\section{Acknowledgements}

None.

\section{Conflict of interest}

Author declares there is no conflict of interest in publishing the article.

\section{References}

1. Weenig RH, Sewell LD, Davis MD, et al. Calciphylaxis: natural history, risk factor analysis, and outcome. J Am Acad Dermatol. 2007;56(4):569-79.
2. Fernandes C, Maynard B, Hanna D. Successful treatment of calciphylaxis with intravenous sodium thiosulfate in a nonuremic patient: case report and review of therapy side effects. J Cutan Med Surg. 2014;18(5):356-60.

3. Hasan Bazari, Michael R Jaff, Michael Mannstadt et al. Case 7-2007: A 59-Year-Old Womanwith Diabetic Renal Disease and Nonhealing Skin Ulcers. N Engl J Med. 2007;356:1049-57.

4. Vedvyas C, Winterfield LS, Vleugels RA. Calciphylaxis: a systematic review of existing and emerging therapies. $J$ Am Acad Dermatol. 2012;67(6):e253-60.

5. Vincent M Brandenburg, Mario Cozzolino, Markus Ketteler. Calciphylaxis: a still unmet challenge. JNEPHROL. 2011;24(02):142-8. 